
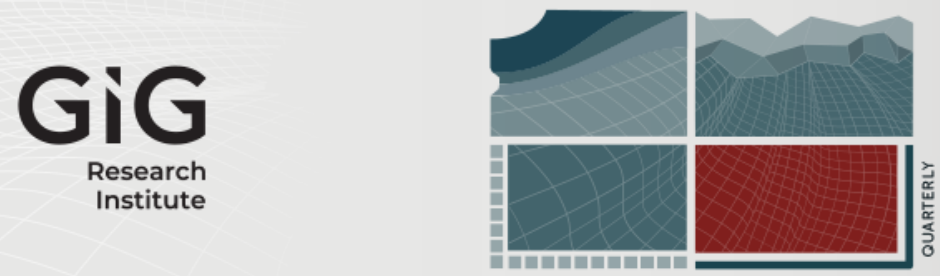

JOURNAL

OF

SUSTAINABLE

MINING

\title{
Investigating the effectiveness of a ground support system implemented on Block A: A case study of Southern Africa Metalliferous Mine
}

Author(s) ORCID Identifier:

Peter Kolapo (iD 0000-0002-8840-1284

Follow this and additional works at: https://jsm.gig.eu/journal-of-sustainable-mining

Part of the Explosives Engineering Commons, Oil, Gas, and Energy Commons, and the Sustainability Commons

\section{Recommended Citation}

Manyelo, Kamogelo and Kolapo, Peter (2022) "Investigating the effectiveness of a ground support system implemented on Block A: A case study of Southern Africa Metalliferous Mine," Journal of Sustainable Mining: Vol. 21 : Iss. 1 , Article 1.

Available at: https://doi.org/10.46873/2300-3960.1344

This Research Article is brought to you for free and open access by Journal of Sustainable Mining. It has been accepted for inclusion in Journal of Sustainable Mining by an authorized editor of Journal of Sustainable Mining. 


\title{
Investigating the effectiveness of a ground support system implemented on Block A: A case study of Southern Africa Metalliferous Mine
}

\begin{abstract}
This study aims to investigate the effectiveness of the ground support systems that are planned to be implemented on Block A, which will be excavated through the Marikana fault zone. The block of ground being prepared for mining has been physically affected by the presence of the Marikana fault and is therefore geomechanically and geotechnically weaker than the normal stoping conditions on the rest of the shaft. Joint mapping conducted in Block A raiselines indicated that there is a high concentration of shallow dipping joints which are dipping in opposite directions. Such conditions present special challenges in the planned excavations because they can lead to sudden and uncontrolled collapses unless appropriate action is taken to mitigate such instances. The orientation of joint sets aid the formation of keyblocks, which can collapse provided their weight exceeds the support load bearing capacity or if they are located in between support units. Therefore, stoping in the Marikana fault zone requires a more intensive support with a higher than normal support resistance. The existing ground control strategies, the processes, tools, techniques, and methods that are currently being used for support design were investigated and incorporated into the new system where applicable.
\end{abstract}

\section{Keywords}

Support system, joint sets, ground support system, rock mass classification, shaft sinking

\section{Creative Commons License}

(c) (1)

This work is licensed under a Creative Commons Attribution 4.0 License. 


\title{
Investigating the effectiveness of a ground support system implemented on Block A: A case study of Southern Africa Metalliferous Mine
}

\author{
Kamogelo Manyelo ${ }^{a, *}$, Peter Kolapo ${ }^{b}$ \\ ${ }^{a}$ University of Witwatersrand, School of Mining Engineering, Faculty of Engineering and Built Environment (FEBE), Johannesburg, \\ South Africa \\ ${ }^{\mathrm{b}}$ University of Kentucky, Department of Mining Engineering, College of Engineering, Lexington, USA
}

\begin{abstract}
This study aims to investigate the effectiveness of the ground support systems that are planned to be implemented on Block A, which will be excavated through the Marikana fault zone. The block of ground being prepared for mining has been physically affected by the presence of the Marikana fault and is therefore geomechanically and geotechnically weaker than the normal stoping conditions on the rest of the shaft. Data collected during the raiselines mapping was used as input into the numerical modelling software (Dips and JBlock), which indicated a major scatter of joint orientations in Block A. Shallow dipping orientations of $276^{\circ} / 14^{\circ}, 174^{\circ} / 11^{\circ}$ and $69^{\circ} / 14^{\circ}$ were observed. An average $\mathrm{RMR}$ below 50 was calculated from the field mapping data which indicates that the quality of the rockmass in Block $A$ is relatively poor and pose the risk of rock falls due to high probability of unstable rocks. Jblock simulations were performed to estimate the load bearing capacity of the roof bolts. The simulation results showed that the probability of failure reduced to $26 \%$ at a loading capacity of $160 \mathrm{kN}$ as opposed to a $60 \%$ probability using $100 \mathrm{kN}$ capacity. Likewise, the probability of block failure for $1 \mathrm{~m}^{3}$ blocks and the maximum support failure decreased to $27 \%$ and $5 \%$ respectively. The area simulated is a stoping panel with a $15 \mathrm{~m}$ face length and a $30 \mathrm{~m}$ back length. A total number of $10000 \mathrm{keyblocks}$ were generated and the probability of failure was highest for $1 \mathrm{~m}^{3}$ at a $60 \%$ in between support. The JBlock analysis shows that the support spacing implemented at Mine A does not sufficiently account for all rockfalls that can occur due to keyblock formation in the hangingwall. In order to effectively support the unstable ground, it is recommended that longer grouted coupling roof bolts of $2 \mathrm{~m}$ length spaced at $1 \times 1.2 \mathrm{~m}$ should be installed, as opposed to the current mechanical end-anchors (ungrouted) of $1.6 \mathrm{~m}$ length spaced at $1.5 \mathrm{~m} \times 1.5 \mathrm{~m}$.
\end{abstract}

Keywords: rockfall, RMR, Q-rating, JBlock, ground support

\section{Introduction}

A ccidents in the mining sector continue to threaten the sustainability of the mining industry. Injuries and fatalities are still a major concern, with the destruction of property being a secondary effect [1]. There has, undeniably, been a substantial improvement in the fatality records within the South African mining industry from 1994 to 2017 as a whole, with a decline in fatalities recorded in hard rock tabular mines [2]. Regardless of these improvements, the loss of life is still too high compared to other large mining countries like the USA, Canada and Australia. The significant causes of injuries and fatalities in the gold and platinum mines in South Africa are due to Falls of Grounds (FOGs), mine ventilation, and transport and machinery issues. According to Shaft P2's Fatality and Injuries Register, $32 \%$ of all fatalities at the shaft are due to FOGs. This is a significantly high number, followed by Machinery at $22 \%$. The register further indicates that a majority of these FOGs highlight the stope face area as the dominant risk area.

As a result of an increased number of discontinuities in Block A, poor ground conditions are

Received 5 July 2021; revised 9 October 2021; accepted 18 October 2021.

Available online 5 January 2022

* Corresponding author.

E-mail addresses: Kamogelo.Manyelo@students.wits.ac.za (K. Manyelo), peter.kolapo@uky.edu (P. Kolapo). 
expected and the strength of the rock mass surrounding the excavation is expected to be lower than normal as a result. Various empirical methods are available to estimate the rock mass strength of jointed rock in order to determine the optimum support. The most prominent methods are rock mass classification systems such as the "Q" and Rock Mass Rating (RMR) systems. Such systems assess and rate the conditions affecting the stability or instability of rock masses surrounding underground excavations and provide support recommendations. Evaluation of mechanical properties of the ground plays important role in fracture determination and in selecting the most suitable regional support for particular strata. This will ensure that the desired levels of stability will be maintained throughout the required life of mine. In short, the mechanical property of the ground is considered as one of the major parameters in designing a stable, safe and economical pit wall [3,4].

In addition to these rating systems, a stereographic projection program (DIPS) was used in conjunction with a probabilistic analysis program (JBlock) to determine unstable wedges that may form in the proposed excavations. The study includes both probability analysis and empirical methods in determining the optimum support design, which was used to form a new standard.

Mine $X$ faces the challenge of a block of ground being prepared for mining in Block A which has been physically affected by the presence of the Marikana fault and is therefore likely to be geomechanically and geotechnically weaker than the normal stoping conditions on the rest of the shaft. Because of this, large stope collapses are expected to occur in Block A if no strategies are put in place to mitigate the risk. To be able to investigate the challenges associated with the extraction of the UG2 reef in Block A which will be excavated through the Marikana fault zone, it is important to provide answers to these questions. How effective is the ground support systems that are planned to be implemented on Block A? Is the support configuration effective? Is the ground over-supported?

This study discusses the challenges faced when extracting ore from the Upper Ground 2 (UG2) reef in Block $\mathrm{A}$ and provides safe and productive mining conditions in the geotechnically poor ground located in Block A, with the aim of achieving zero harm and providing an efficient and cost-effective support design. The workings developed across Block A are planned to extract only the UG2 Reef. Therefore, this study will focus predominantly on the support design for the stratigraphy above the UG2 Reef.

\section{Description of the study area}

Shaft P2 and Shaft P3 at Mine X form part of the mine's second-generation shafts. That is, the newer shafts to be sunk and operated. The shafts are located approximately $25 \mathrm{~km}$ West-South-West of Brits (North West Province of South Africa). The shafts fall within the western limb of the Bushveld Igneous Complex, a large igneous intrusion which is host to some of the Platinum Group Elements (PGEs). Mine $X$ exploits PGEs from the UG2 and Merensky reefs. Shaft P2's operation faces the challenge of rapidly depleting ore reserves for both UG2 Chromitite and Merensky reef types within its current shaft boundaries. However, exploration and feasibility studies (conducted by the Geology department at the mine) led to the extension of Shaft P2 operations beyond the Marikana fault zone into the mineral resource area of the P3 Shaft block (see Fig. 1). Mining on the other side of the fault is expected to increase the life-of-mine of Shaft P2 by another five years i.e. until 2026. Stopes and haulages are planned to be developed through the Marikana fault zone which is dipping in a SSENNW direction. The Marikana fault is a reverse fault (dipping approximately $80^{\circ}$ ) with an up-throw displacement to the west of approximately $10-20 \mathrm{~m}$. Stoping in the Marikana fault zone requires a more intensive support with a higher than normal support resistance. Several types of support such as grout packs and roof bolts are planned to achieve the projected safety requirement.

At Mine X, the UG2 underlies the Merensky Reef by approximately $130-210 \mathrm{~m}$, increasing from west to east across the Marikana operations [5]. As a result of the variable stratigraphic distance between these ore bearing horizons, each of these reef horizons is influenced by different geological features [6]. The geological sequence in Fig. 2 shows alternating layers

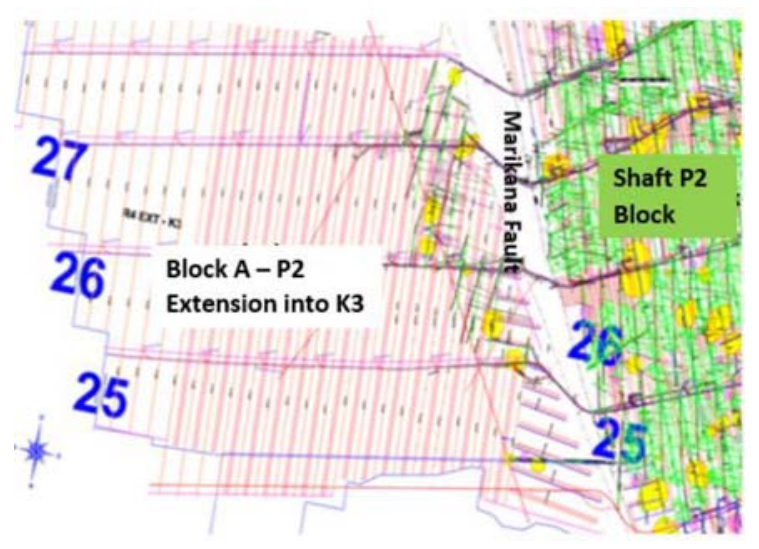

Fig. 1. Image showing the Marikana fault zone. 


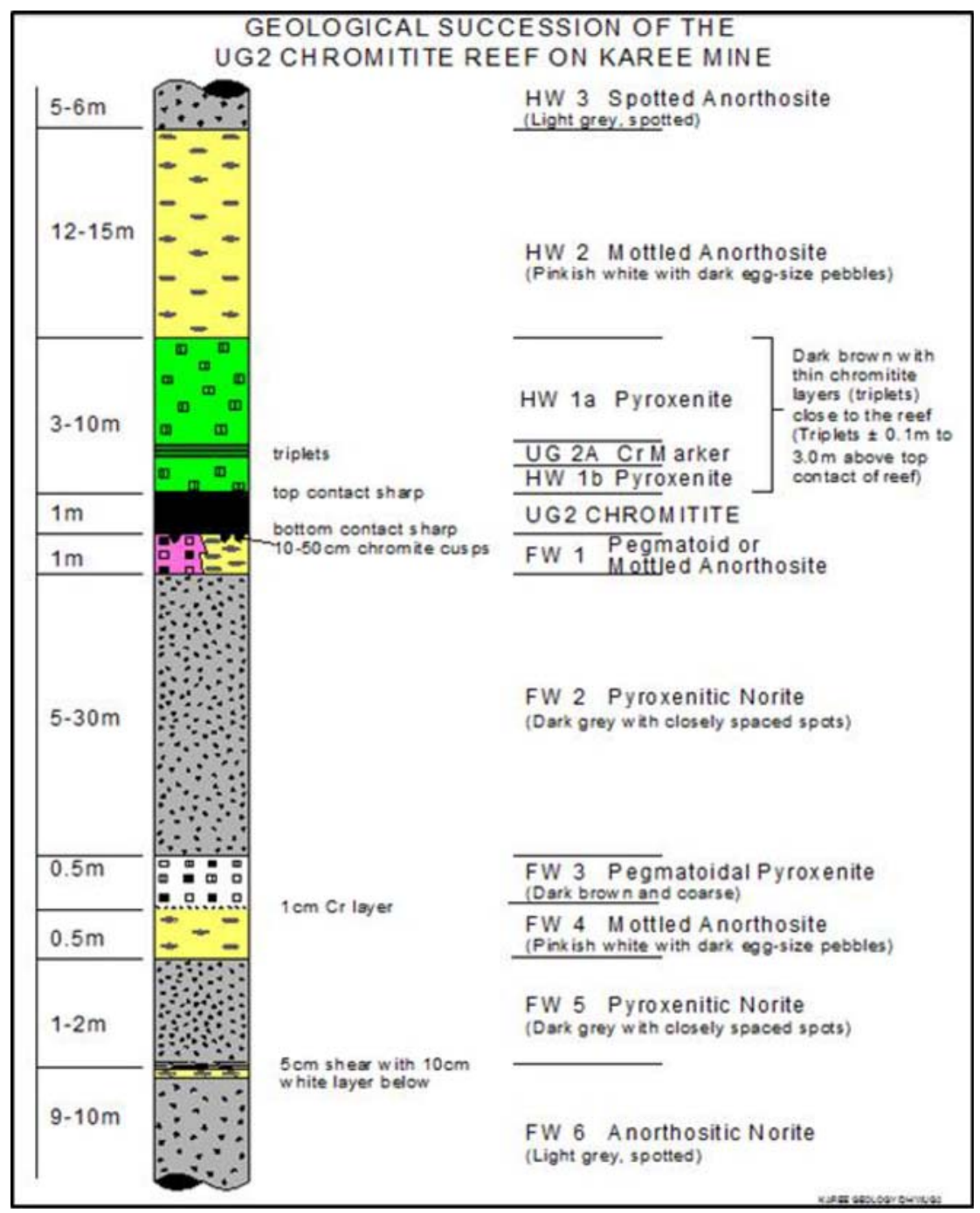

Fig. 2. Typical stratigraphic column showing the lithology of the UG2 Reef in Block A.

of pyroxenite, norite, mottled anorthosite and chromitite. Across the mine, the general mining layout is an up-dip configuration with dip stabilizing pillars, stoping through two panels on either side of a center raise at a panel length of $15 \mathrm{~m}$. Block $A$ is planned to exploit the UG2 Chromitite Reef in this type of stoping configuration.

The strike of the UG2 orebody in Block A is on average East to West and dipping towards the North at an average angle of $9^{\circ}$, with a thickness variance of $0.4-1 \mathrm{~m}$. The geotechnical environment most likely to be encountered by mining in Block A include:

- Geological structures;

- Alteration zones; and

- Parting planes.

The following section provides a general description of the geotechnical environment in which key design parameters for support design will be described.

\subsection{Jointing}

Joints are naturally occurring planar geological discontinuities across which there has been no displacement. Joint structures are a predominant feature in most underground operations across the Mine X lease area. The stability of underground mining excavations is highly dependent on the occurrence and orientation of jointing in the surrounding rockmass. An unfavorable intersection of joints may lead to blocky hangingwall conditions, which can lead to instability and failure if not supported. The presence of joints in the hangingwall causes a discontinuous rockmass which contains interlocking blocks that are bounded by the joint surfaces or infilling material. Natural rock joints 
infilled with soil-like materials may show a reduced shear strength, which influences rock mass stability.

Both open (i.e. open fractures) and sealed (filled by various materials) joints were identified during the underground joint mapping along the raiselines in the Visser Block. Like the faults, joints vary in strike, and dip orientations as well as filling and persistency characteristics. Low angle joints i.e. shallow dipping joints cutting into the hangingwall can cause FOGs, particularly when these joint sets dip in opposite directions because of the formation of keyblocks.

\subsection{Potholes}

Potholes are roughly circular or elliptical structures where the UG2 reef and lithologies immediately above it slumped to a lower level during geological processes, causing the UG2 chromitite to occur below its normal stratigraphic elevation. The thinning of the reefs and increased joint densities often marks the rims of potholes. Pothole occurrences are not predictable, and their presence in the Visser Block has been partially determined by cover drilling and mining development. When mining approaches a pothole, the joint density usually increases. Where visible, low angle jointing was found on the edges of the potholes. This should be taken into consideration when approaching a pothole. In such situations, hangingwall beam stability becomes more challenging.

\subsection{Faulting}

Faults are planes of weakness in the rockmass where movement has occurred along the plane. Three types of faults are encountered in the Mine X Marikana lease area; normal faults, reverse faults and strike-slip faults [5]. Faulting presents a challenge when mining towards or through it, as an increase in jointing can occur and the infilling material may create an unstable work environment. Historical information shows that adverse ground conditions are encountered when mining areas of a fault and can cause falls of ground, as some faults have very little cohesion on the plane of weakness where movement has occurred. A trend of minor faulting occurs within both the shaft P2 and K3 block areas; these faults have an east-southeast to west-northwest striking direction and are mostly reverse faults, but rarely with more than $2 \mathrm{~m}$ displacements. There are indications of smaller faults with the same orientation as the Marikana fault. These faults are increased in frequency closer to the
Marikana fault. This indicates the high stress concentrations within the surrounding rock mass.

\subsection{Alteration}

Alteration occurs when there is a change in the structure of a rock or rockmass where water and other minerals have intruded into planes of weakness to change the structure and minerality of the rock mass surrounding the plane. Often referred to as weathering, these changes can make the rock mass weak and brittle. Alteration is typically present in the vicinity of dykes, faults and joint zones. The alteration of the rock surrounding geological structures depends on the mineralogy of the joint infilling and in the Mine X Marikana lease area, chlorite and serpentine are the most susceptible. This is most prominent in the pyroxenite hangingwall. The Block $\mathrm{A}$ is expected to have a large alteration area influenced by the Marikana fault striking through the mining block. Observations made in the haulages show that the area around the fault is altered and is expected to present a number of mining difficulties. Figure 3 shows the alteration occurring through hangingwall layers above the UG2 Reef in the Block A. Alteration can be seen in jointing and the layer contact plane in between the Hangingwall 1 (HW1b) and Hangingwall 2 (HW2).

\section{Literature review}

A great number of studies have indicated several methods of determining underground support requirements. Although, this background study will focus on the application of rock mass classification systems can be used to determine the support requirements for Block A. The focus is on contributions made by relevant experts in rock mechanics on qualitative and quantitative analysis.

Hoek [7] stated that great improvements can be achieved in the underground excavations through the use of design and timeous installation of support, taking into account excavation sequences and availability of materials. Rock mass classification systems, particularly the $Q$-system developed by Barton [8] express the quality of the rock mass using an empirical formula. The $Q$-value is determined from the grouping of six quantifiable geological parameters, in order to provide a value to quantify the rock quality in stable and unstable geotechnical conditions. Based on the following parameters, the $Q$-value for a rock mass can be calculated using the following equation Barton [8]. 


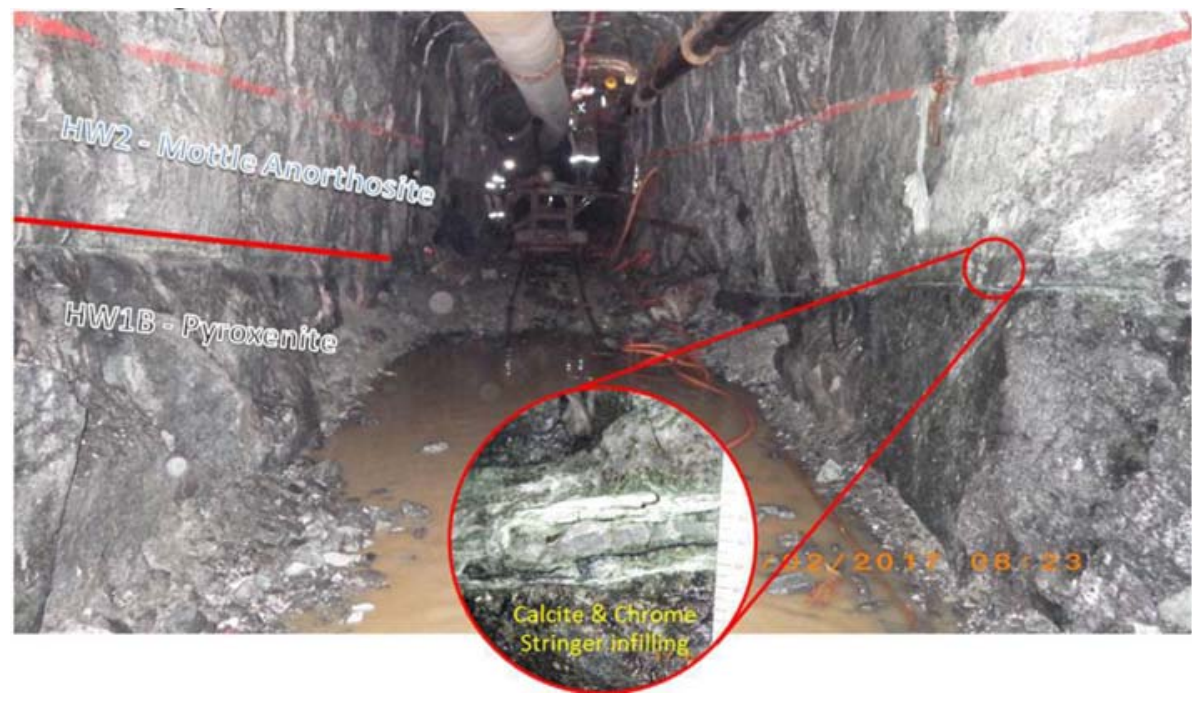

$Q=\frac{R Q D}{J_{n}} \times \frac{J_{r}}{J_{a}} \times \frac{J_{w}}{S R F}$

where:

- $J_{n}$ : is the joint set number

- ${ }_{r}$ : is the joint roughness number. According to Watson [9] "such a critical joint set that is planar and either slicken sided or with a smooth or gouge infilling could cause a panel collapse".

- $J_{a}$ : is the joint alteration number. Panel collapses frequently occur when $J_{a}$ is larger than 3 when making use of the $Q$-system [9].

- $J_{w}$ : is the joint water reduction factor. This value indicates the quantity of water present in a joint, which has an adverse consequence of reducing the strength of the host rockmass.

- SRF: Stress Reduction Factor is "a measure of the loosening load in cases of excavations with shear zones and clay bearing rocks" [10].

- $(R Q D)$ - Rock Quality Designation is a measure of the degree of jointing and was modified by Palmstrom [11] for use in rockmass exposure i.e. where no core is available. The equation is as follows:

$R Q D=115-3.3 J_{v}$

Low quality rock has an $R Q D$ of less than $50 \%$ whereas high quality rock has an $R Q D$ of above $75 \%$. Equation (2) is estimated from the number of joints encountered per unit volume $\left(J_{v}\right)$ of the rockmass, where blast induced discontinuities are omitted. This concept was introduced by Palmstrom [11] and provides an easy approach of approximating the degree of jointing from standard joint mapping data or observations.
Additionally, Rock Mass Rating (RMR) derived by Bieniawski [12] consider the summing 5 parameter values and adjusting this total by taking into account the joint orientations. The parameters included in the rating include the Uniaxial Compressive Strength (UCS), rock quality designation (RQD), spacing of discontinuities, conditions of discontinuities, groundwater conditions, and orientation of discontinuities. The $R M R$ system is described by Bieniawski [12] as follows:

$R M R=9 \ln Q+44$

Swart [13] stated that rock mass classification approaches cannot be adequately used to analyze structurally controlled failures such as beam, block and wedge. They further state that "although rock mass classification should form a fundamental part in the process of designing stable stope panels, particular emphasis should be placed on identifying the most likely failure planes and potential modes of failure". Both the Q- and RMR system are internationally accepted and used in rock engineering as empirical design tools for stable excavations.

More recently, existing rock mass classification systems have been developed and even modified to suit local conditions. Watson [9] reviewed several systems and concluded that the modified stability graph by Potvin [14] only described unsupported stopes. The study designed a hybrid of several current systems and termed it the "New Modified Stability Graph" (N") system. The system is intended specifically for span and support design in stopes of the Bushveld Complex Platinum. Subsequently, databases of failed and unfailed stopes were collected for the Merensky Reef with various support resistances. A logistical regression analysis 
was used to determine the line between stable and unstable stopes, with various degrees of confidence. The system makes use of aspects from various rating systems and is currently used by Impala Platinum. The system also incorporates the $Q$-system and the Stability Graph method as revised by Hutchinson and Diederichs [15]. It consists of the following five factors Watson [9]:

- "a measure of block size for a jointed rock mass (RQD/Jn).

- a measure of joint surface strength and stiffness $(J r / J a)$.

- a measure of the stress condition (Jw/SRF)

- a measure of the joint orientation relative to the excavation hangingwall (B-factor); and

- a measure of the influence of gravity on the hangingwall blocks (C-factor)."

Although the system is designed specifically for mines in the Bushveld complex, it cannot be used to fully meet the objectives of this project. Its limitations are that it focuses predominately on panel spans in the Merensky Reef. It is the opinion of the experts in underground excavations that rockmass classification systems as a designing tool on their own should be used for preliminary designs of underground openings, that is, for planning purposes and not for final excavation support.

\section{Materials and methods}

The objective of this study was to provide a support design based on a proper knowledge of the inclination, orientation and intensity of the geological features that exist in Block A. Data on the inclinations and orientations of geological features, particularly faults and joints were collected from existing raiselines in the area of Block A. Five meter long scanlines were conducted at $30 \mathrm{~m}$ intervals along each of the seven raiselines and winzes in Block A. Measurements were taken with a Silva foldable geological compass and frequently checked with a $1 \mathrm{~m}$ clino-rule to ascertain the possible influence of magnetic substances on the readings shown in Figs. 4 and 5 respectively. The clino-rule is a $1 \mathrm{~m}$ long device fitted with a water bubble and a linear scale used for the estimation of the length and dip orientation of discontinuities. The Silva compass is an instrument used to magnetically determine dip and dip-direction. The following parameters were determined from the joint mapping.

Joint sets were delineated based on observations i.e. classified according to their orientations. These joint sets and the above-mentioned parameters within the block were geotechnically evaluated and the results entered into the form reproduced in Table 1.

The joint set most likely to result in hangingwall failure was distinguished and used in defining the joint roughness and alteration. Blasting fractures and structures with a trace length of less than $0.5 \mathrm{~m}$ were not considered. From observations, such structures can be easily identified and addressed by barring or areal coverage support where required, provided entry examination is conducted correctly. The $R Q D$ was estimated from the number of discontinuities per unit volume as suggested by Palmstrom [11]. Joint roughness was determined by measuring offsets across the joint, such that the largest offset is related to the "joint roughness number" (Jr) [9].

The results from underground joint mapping were used as input data into DIPS software so as to analyze and graphically represent structural data by the use of stereonet. Stereographic projections provide a means of representing the $3 \mathrm{D}$ orientations of planes in 2D. Joint sets can be clustered and analysed from a pole plot generated in DIPS. This was done by drawing a window set around the poles concentrated in a specific area to group data related to a specific joint set. Figure 5 depicts a pole and contour plot from DIPS. Orientation,

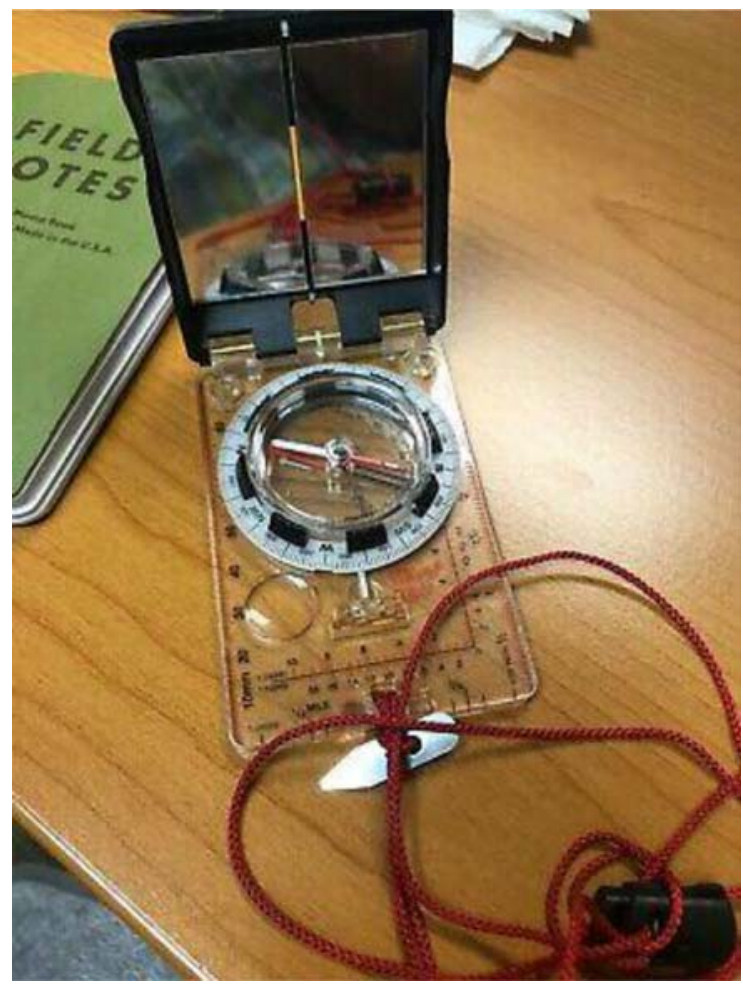

Fig. 4. Image of Silva foldable geological compass. 


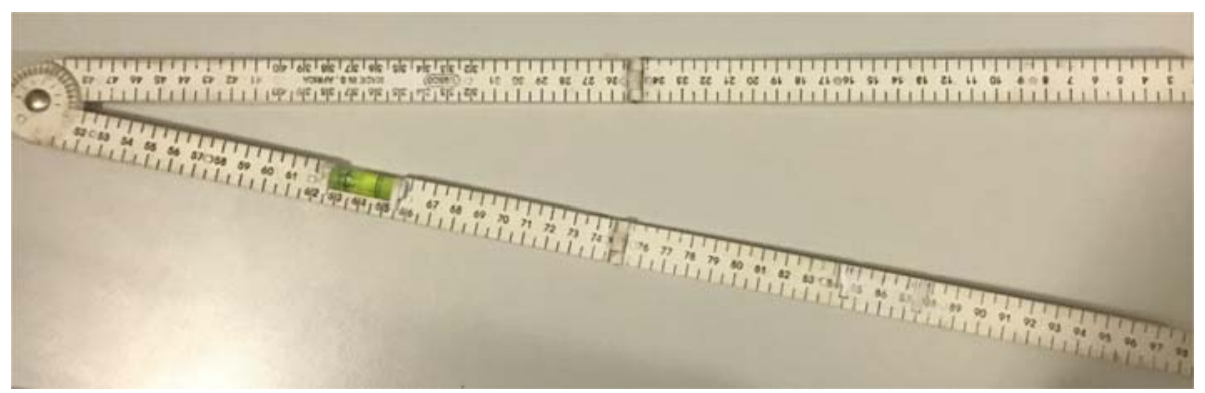

Fig. 5. Image of $1 \mathrm{~m}$ clino-rule.

Table 1. Joint mapping table template.

Date:

Panel Number:

Depth below surface:

\begin{tabular}{|l|l|l|l|l|l|l|l|l|l|}
\hline $\begin{array}{l}\text { Joint } \\
\text { Set } \\
\text { Number }\end{array}$ & $\begin{array}{l}\text { Orientation } \\
\text { (Dip } \\
\text { Angle/Dip } \\
\text { Direction) }\end{array}$ & Length & Infill & Roughness & $\begin{array}{l}\text { Infill } \\
\text { Type }\end{array}$ & $\begin{array}{l}\text { Joint } \\
\text { Spacing }\end{array}$ & $\begin{array}{l}\text { Presence of } \\
\text { Water }\end{array}$ & $\begin{array}{l}\text { Rock } \\
\text { RQD }\end{array}$ & Remarks \\
\hline & & & & & & & & & \\
\hline & & & & & & & & & \\
\hline & & & & & & & & & \\
\hline & & & & & & & & & \\
\hline & & & & & & & & & \\
\hline & & & & & & & & & \\
\hline
\end{tabular}

true spacing, trace lengths and friction angles were calculated from data related to specific joint sets. The orientation of the parting planes was also used as input into the software. This was done in order to determine the possibility of intersection of these parting planes and joint sets, and the geometry of their intersection. The data on joint orientations collected in a joint mapping exercise were plotted on a polar plot (indicating dip and dip directions).

JBlock software was used as a primary method of analysis in order to determine the frequency of different sized keyblocks and their stability. A multiple block analysis was run so as to evaluate blocks which are randomly created as a result of natural joints and stress fractures in the hangingwall. The spacing between the joints, orientation and length of the joints was used data. Additionally, the support properties in terms of spacing, support load bearing capacity and length were used. A histogram was produced as an output from the exercise and blocks with different volumes plotted. These blocks had different probabilities of failure in different size intervals. The exercise was done at different input parameters of length, spacing and capacity in order to determine the optimum support standard.

\subsection{Results}

The results of the study with regards to the rock mass classification, JBlock and Dips simulations are described below. All measurements and derived results are tabulated and plotted graphically.

\subsubsection{Rockmass rating}

The Barton [8] approach was used to classify the rock mass in narrow reef stopes prior to excavation to establish the underground excavation which is termed raiseline (RSE). A total number of seven raiselines (RSE) were classified (RSE 1 to RSE 7) and their respective rock mass ratings were presented as shown in Table 2.

The $R M R$ rating results indicate that only one raiseline had good ground conditions, with the rest of the six raiselines having a poor rating. A majority of these raiselines are close to the boundaries of poor and good rock categories. 
Table 2. Rockmass rating.

\begin{tabular}{|c|c|c|c|c|c|c|c|}
\hline Parameter & RSE 1 & RSE 2 & RSE 3 & RSE 4 & RSE 5 & RSE 6 & RSE 7 \\
\hline $\begin{array}{l}\text { Volumetric joint } \\
\text { count (Joints/m3) }\end{array}$ & 9.38 & 6.23 & 5.4 & 3.8 & 4 & 5.4 & 11.73 \\
\hline RQD & 84.04 & 94.45 & 97.18 & 100 & 100 & 97.18 & 76.3 \\
\hline \multicolumn{8}{|l|}{ Q-Rating } \\
\hline Joint set number (Jn) & 4 & 4 & 4 & 4 & 4 & 4 & 4 \\
\hline $\begin{array}{l}\text { Joint roughness } \\
\text { number (Jr) }\end{array}$ & 1.5 & 1 & 2 & 2 & 2 & 2 & 1 \\
\hline $\begin{array}{l}\text { Joint alteration } \\
\text { number (Ja) }\end{array}$ & 2 & 2 & 2 & 4 & 2 & 4 & 4 \\
\hline Joint water (Jw) & 1 & 1 & 1 & 1 & 1 & 1 & 1 \\
\hline $\begin{array}{l}\text { Stress reduction factor } \\
\text { (SRF) }\end{array}$ & 7.5 & 2.5 & 7.5 & 2.5 & 7.5 & 7.5 & 2.5 \\
\hline Adjustment for UG2 & 1 & 1 & 1 & 1 & 1 & 1 & 1 \\
\hline Q-Rating & 1.85 & 3.37 & 2.86 & 6.25 & 2.94 & 1.43 & 1.36 \\
\hline RMR Rating & 49.6 & 54.9 & 53.5 & 60.5 & 53.7 & 47.2 & 46.8 \\
\hline Quality of Rock & Poor & Poor & Poor & Good & Poor & Poor & Poor \\
\hline
\end{tabular}

\begin{tabular}{|c|l|}
\hline \multicolumn{2}{|c|}{ Q-Result } \\
\hline \multicolumn{2}{|c|}{} \\
\hline 0.005 to 0.9 & Very Poor \\
\hline 1 to 5 & Poor \\
\hline 6 to 10 & Good \\
\hline $10+$ & Very Good \\
\hline RMR - Result \\
\hline $0-40$ & Very Poor \\
\hline $41-55$ & Poor \\
\hline $56-65$ & Good \\
\hline $66-100$ & Very Good \\
\hline
\end{tabular}

Table 3. Summary of the major joint sets characteristics.

\begin{tabular}{|c|c|c|c|c|c|c|c|c|}
\hline \multirow[t]{2}{*}{ Joint Set } & \multicolumn{2}{|c|}{ Orientation } & \multicolumn{3}{|c|}{ Spacing (m) } & \multicolumn{3}{|c|}{ Length (m) } \\
\hline & Dip & $\begin{array}{l}\text { Dip } \\
\text { Direction }\end{array}$ & Min & Mean & Max & Min & Mean & Max \\
\hline J1 & 14 & 276 & 0.1 & 0.94 & 1 & 2 & 2.2 & 2.5 \\
\hline J2 & 11 & 174 & 0.05 & 1.2 & 3 & 1.8 & 2.1 & 3 \\
\hline J3 & 14 & 69 & 0.1 & 0.9 & 1 & 1.5 & 1.8 & 2.2 \\
\hline
\end{tabular}

\subsubsection{Numerical modelling}

The software analysis indicated that there is a major scatter of joint orientations in Block A. However, three joint sets were defined. The dominant set is termed set $1 \mathrm{~m}$ followed by set $2 \mathrm{~m}$ and set $3 \mathrm{~m}$, where the latter set is the least dominant. The remaining joints mapped are random joints. Average orientations of sets $1 \mathrm{~m}$ and $2 \mathrm{~m}$ and $3 \mathrm{~m}$ are $276^{\circ} / 14^{\circ}, 174^{\circ} / 11^{\circ}$ and $69^{\circ} / 14^{\circ}$ respectively, implying that they are shallow dipping. Joint set $1 \mathrm{~m}$ and $3 \mathrm{~m}$ are dipping in opposite directions and can form keyblocks. Where these joints intersect with the triplets (labeled as 1 on the stereonet with the orientation of $360^{\circ} / 9^{\circ}$ ), keyblocks are formed. These keyblocks can cause the collapse of the strata below the triplets if not supported correctly. The triplets is a colloquial term for chromitite stringers which characterize the hangingwall of the UG2 reef. The triplets are taken into consideration when designing a support standard because of their weak cohesive properties.

Most of the joints in the stopes were unfilled. However, the few filled joints observed were steeply dipping and chlorite and serpentine as the filling material, with a thickness ranging between 1 and
$3 \mathrm{~cm}$. Table 3 describes the joint properties of the three major joint sets defined. These properties were used as input data in JBlock in order to generate keyblocks to determine probabilities of failure.

From the joint mapping result, underground joint mapping were plot as input data into DIPS software to provide the structural data as shown in Fig. 6.

The results of JBlock simulations are indicated in Figs. 7 and 8. These results represent the frequencies of different sized keyblock distributions and probabilities that these keyblocks would fail. Geotechnical data was collected using scanline mapping methods. The joint data was analysed using Rocscience's Dips. Jblock was then used to compare the different support scenarios. Potential keyblocks are generated based on the geotechnical file and an excavation file in JBlock. The geotechnical file describes the ground conditions to assess. Due to insufficient fall out thickness data to dictate the parameters of the design, the highest value was used from the surrounding Ground Control Districts (GCD's) to account for the worst expected scenario based on recorded data. The thickness used was therefore $1.2 \mathrm{~m}$ as found in the surrounding GCD's.

In order to determine the optimum load bearing capacity for the roof bolts, simulations were done at different support spacings and different support bearing capacities. The results are indicated in Figs. 9 and 10. It is evident that at a load bearing capacity of $160 \mathrm{kN}$, there is a reduced probability of failure at $26 \%$ in between support as opposed to a $60 \%$ probability using $100 \mathrm{kN}$ capacity. Furthermore, 


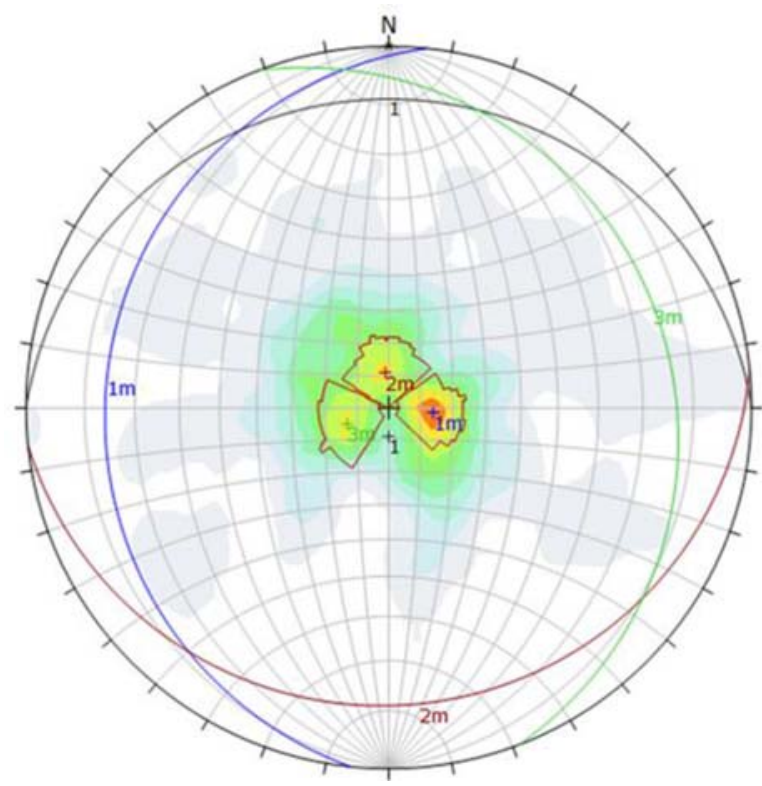

\begin{tabular}{|c|c|c|c|c|c|}
\hline \multicolumn{2}{|c|}{ Color } & \multicolumn{4}{|c|}{ Density Concentrations } \\
\hline & & \multicolumn{4}{|c|}{$0.00 \cdot 0.60$} \\
\hline & & \multicolumn{4}{|c|}{$0.60-1.20$} \\
\hline & & \multicolumn{4}{|c|}{ - 1.80} \\
\hline & & \multicolumn{2}{|c|}{$1.80 \cdot 2.40$} & & \\
\hline & & \multicolumn{4}{|c|}{$2.40 \cdot 3.00$} \\
\hline & & \multicolumn{4}{|c|}{$3.00-3.60$} \\
\hline & & \multicolumn{4}{|c|}{$3.60-4.20$} \\
\hline & & \multicolumn{4}{|c|}{$4.20-4.80$} \\
\hline & & \multicolumn{4}{|c|}{$4.80-5.40$} \\
\hline & & \multicolumn{4}{|c|}{$\begin{array}{r}5.40 \\
-6.00\end{array}$} \\
\hline & & \multicolumn{2}{|c|}{ Contour Data } & \multicolumn{2}{|l|}{ Pole Vectors } \\
\hline & \multicolumn{3}{|c|}{ Maximum Density } & \multicolumn{2}{|l|}{$5.34 \%$} \\
\hline & \multicolumn{3}{|c|}{ Contour Distribution } & \multicolumn{2}{|l|}{ Fisher } \\
\hline & \multicolumn{3}{|c|}{ Counting Circle Size } & \multicolumn{2}{|l|}{$1.0 \%$} \\
\hline & Color & Dip & Dip & Direction & Label \\
\hline \multicolumn{6}{|c|}{ User Planes } \\
\hline 1 & & 9 & & 360 & \\
\hline \multicolumn{6}{|c|}{ Mean Set Planes } \\
\hline in & & \multirow{2}{*}{\multicolumn{4}{|c|}{$\begin{array}{ll}14 & 276 \\
11 & 174\end{array}$}} \\
\hline $2 \pi$ & & & & & \\
\hline 3n & & \multirow{2}{*}{\multicolumn{3}{|c|}{\begin{tabular}{|c|c}
14 & 69 \\
Plot Mode & Pole Vectors \\
\end{tabular}}} & \\
\hline & & & & & \\
\hline & & \multicolumn{2}{|c|}{ Vector Count } & \multicolumn{2}{|c|}{882 (832 Entries) } \\
\hline & & \multicolumn{2}{|c|}{ Hemisphere } & \multicolumn{2}{|l|}{ Lower } \\
\hline & & \multicolumn{2}{|c|}{ Projection } & \multicolumn{2}{|l|}{ Equal Angle } \\
\hline
\end{tabular}

Fig. 6. Stereonet projections of major joint sets identified.
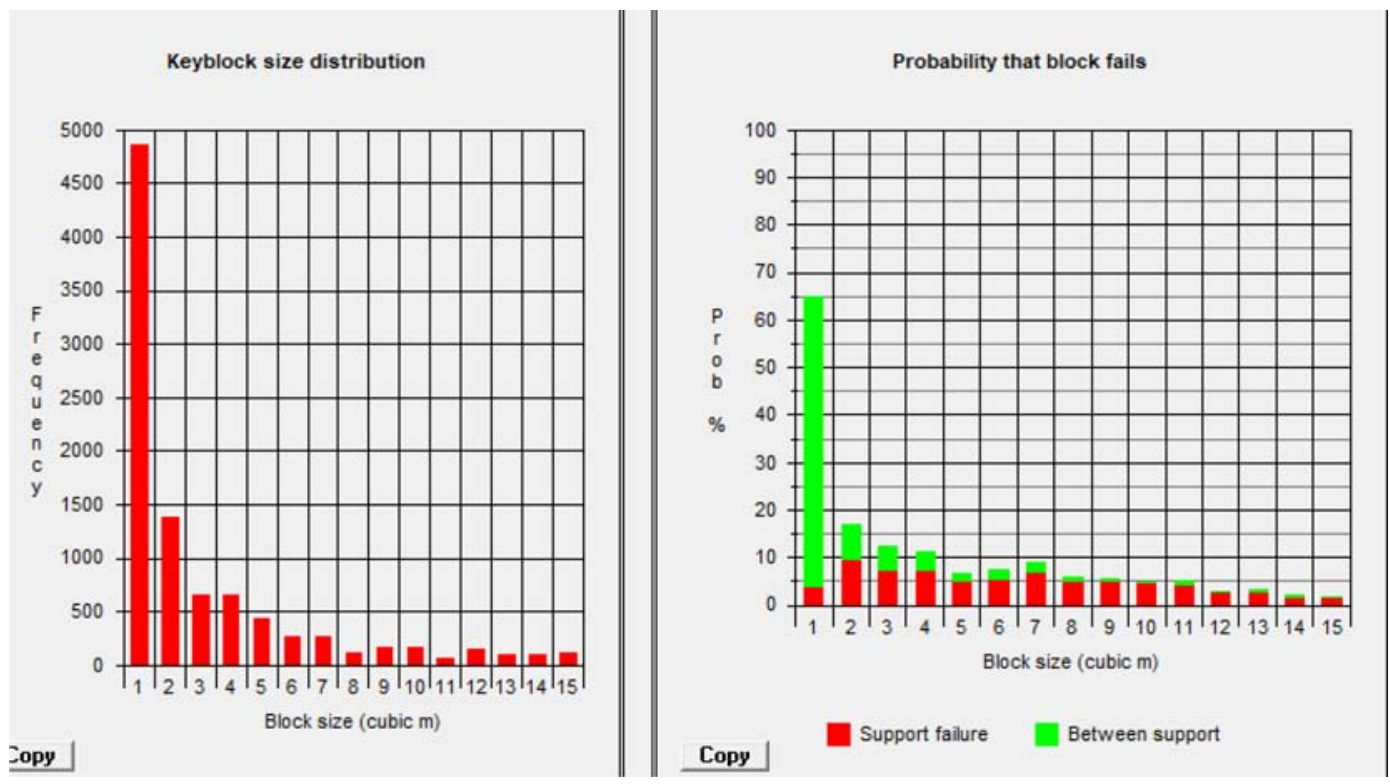

Fig. 7. Probability of block failure based on the current support system.

Fig. 5 indicates that at a spacing of $0.5 \mathrm{~m} \times 1.2 \mathrm{~m}$ and a load bearing capacity of $160 \mathrm{kN}$, the probability of keyblock failure as a result of support is $5 \%$ as opposed to $17 \%$ at a capacity of $100 \mathrm{kN}$.

\section{Discussions}

Results from the rock mass classification approach showed that the average $R M R$ calculated was below 50 , which indicates that the quality of the rockmass in Block A is relatively poor. From this, it can be reasoned that the ground conditions in this area pose a high risk of rock falls due to high probability of unstable blocks.

Plotting the dip and dip directions allowed for the visual depiction of the variability of joint orientations. Contouring the pole plots also allowed for the dominant joint sets to be identified. The stereonet results from DIPS indicated that there are three prominent joint sets dipping in opposite directions and intersecting triplets. Where these joint sets (set $1 \mathrm{~m}$ and set $3 \mathrm{~m}$ ) intersect the triplets, a wedge is 

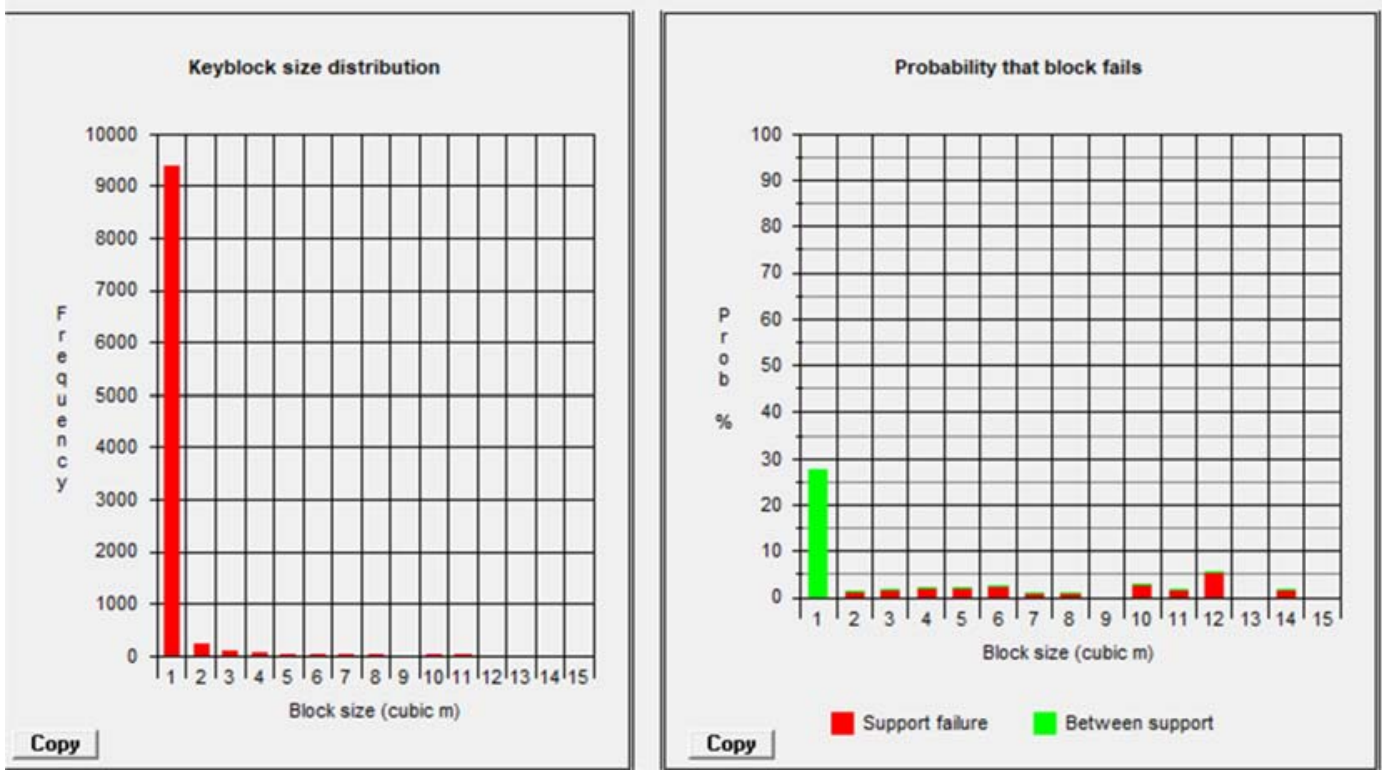

Fig. 8. Probability of block failure based on the new support system.

formed. This means that the support designed has to be able to support the hangingwall beam up to $2 \mathrm{~m}$ into the hanging wall where the triplets are encountered.

JBlock was used to determine the probability of failure of keyblocks in the stope. The structural data for the three joint sets, together with tendon and grout pack data, were used to simulate unstable keyblocks. The mechanism of failure for this analysis is either due to the keyblock size being less than the support spacing, or the keyblock being of such a size that it causes the support unit to be overloaded.
The JBlock model used joint data collected from Mine X underground workings, which included three joint sets as well as a parting plane in the hanging wall at an average depth of $1.9 \mathrm{~m}$ above the hangingwall surface, as indicated in the block A's isopach layout. A standard deviation of 1.2 in terms of the parting plane depth was included in the model.

The unstable keyblocks were simulated by first using the current support system of $1.6 \mathrm{~m}$ long ungrouted roof bolts spaced 1.2 by $1.2 \mathrm{~m}$, with a $100 \mathrm{kN}$ load bearing capacity and $750 \mathrm{~mm}$

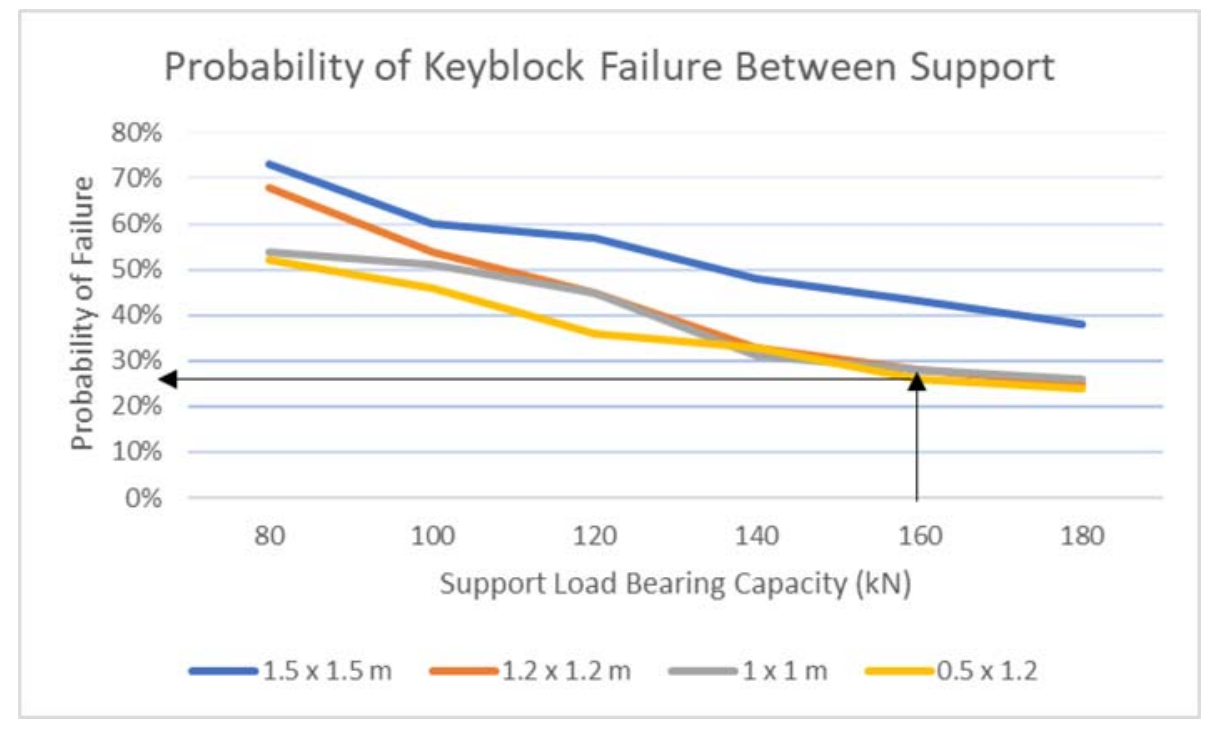

Fig. 9. Probability of Keyblock failure in between support elements. 


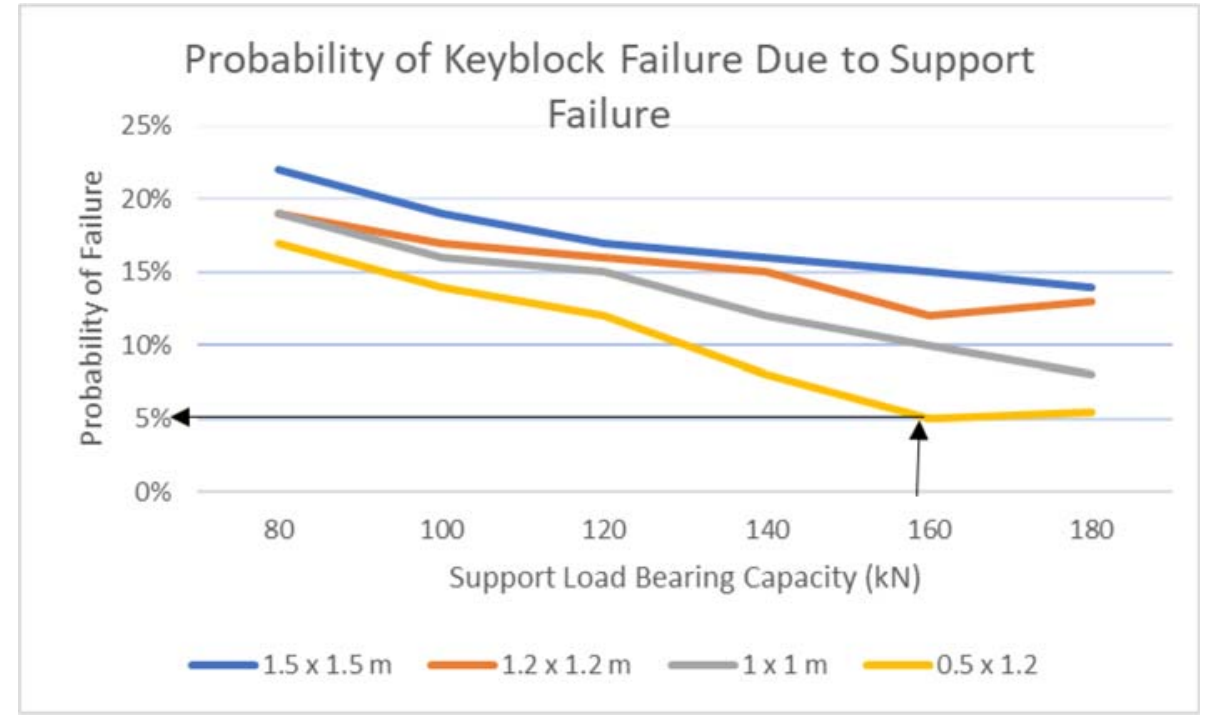

Fig. 10. Probability of Keyblock failure in between support elements.

diameter grout packs with a load bearing capacity of $2200 \mathrm{kN}$. The area simulated is a stoping panel with a $15 \mathrm{~m}$ face length and a $30 \mathrm{~m}$ back length. A total number of 10000 keyblocks were generated and the probability of failure was highest for $1 \mathrm{~m}^{3}$ at a $60 \%$ probability of failure in between support. This suggests that the probability of block failure obtained is high, thus indicating that the support is insufficient. The support spacing was too wide and resulted in a greater percentage of $1 \mathrm{~m}^{3}$ keyblocks falling in between support. The findings indicated that the planned support system for Block A is not sufficient and requires a higher support resistance.

The recommended support system consists of grouted tendons with a load bearing capacity of $160 \mathrm{kN}, 2.2 \mathrm{~m}$ length, and spaced at $0.5 \times 1.2 \mathrm{~m}$. The new support system yields the results shown in Fig. 7. The probability of block failure for $1 \mathrm{~m}^{3}$ blocks decreases to $27 \%$, and the maximum support failure to $5 \%$. The JBlock analysis shows that the support spacing implemented at Mine $X$ does not sufficiently account for all rockfalls that can occur due to keyblock formation in the hangingwall.

\section{Conclusion and recommendations}

This study demonstrated that the current support system using ungrouted tendons $1.6 \mathrm{~m}$ in length spaced at $1.5 \mathrm{~m}$ by $1.5 \mathrm{~m}$ in Block A will not be effective. After the FOS was determined to comply with the required standards, a JBlock analysis had to be done to show whether the support spacing successfully keeps fall of ground from occurring as a result of keyblock failure. The mechanism of failure for this analysis is either due to the keyblock size being less than the support spacing, or the keyblock being of such a size that it causes the support unit to be overloaded. The results from JBlock simulations indicated that there was a high probability of unstable blocks of rock found in the hangingwall in the study raiselines, which are delineated by naturally occurring joints and fractures. These blocks, identified as keyblocks, will collapse if their weight exceeds the support load bearing capacity or if they are located between support units. It is recommended that the mine considers the probabilistic approach in order to determine the suitability and effectiveness of support systems particularly in circumstances where large numbers of discontinuities or stress fractures are exposed in excavations. The results from the DIPS analysis proved that the interaction of the low angle joint sets with the triplets can result in large collapses considering the formation of wedges.

It is recommended that a further study is conducted on the recommended support standard. Longer grouted coupling roof bolts of $2 \mathrm{~m}$ length spaced at $1 \times 1.2 \mathrm{~m}$ are proposed, as opposed to the current mechanical end-anchors (ungrouted) of $1.6 \mathrm{~m}$ length spaced at $1.5 \mathrm{~m} \times 1.5 \mathrm{~m}$. The $2 \mathrm{~m}$ roof bolts would prove to be more expensive than the current roof bolts because of the need for grouting and the increase in support density. However, there is an improvement in safety when considering 
the recommended support system. Mining in Block A has proven to be geotechnically challenging as compared to other stoping conditions at Shaft P2. Ground conditions should therefore be assessed regularly. It must be noted that mining strategy and support regime might be reviewed depending on prevalent ground conditions as panels advance due to extreme variations in properties of the Marikana fault zone. Welded mesh, cable anchors, shotcrete and trusses should be considered depending on the change in ground conditions. The main conclusion that can be drawn from Figs. 4 and 5 and Tables 2 and 3 is that increasing support spacing may not result in unsafe conditions provided entry examination procedure is followed.

\section{Conflict of interest}

None declared.

\section{Ethical statement}

The authors state that the research was conducted according to ethical standards.

\section{Funding body}

None.

\section{References}

[1] Bonsu J, Van Dyk W, Franzidis J-P, Petersen F. A systemic study of mining accident causality: an analysis of 91 mining accidents from a platinum mine in South Africa. J S Afr Inst Min Metall 2017;117:59-66.

[2] Kotze C. Mining review Africa. 2018. Available at: https:// www.miningreview.com/health-and-safety/dmr-decreasefatalities-2018-safety.

[3] Kolapo P. Investigating the effects of mechanical properties of rocks on specific energy and penetration rate of borehole drilling. Geotech Geol Eng 2021;39(2):1715-26.

[4] Kolapo P, Munemo P. Investigating the correlations between point load strength index, uniaxial compressive strength and Brazilian tensile strength of sandstones. A case study of QwaQwa sandstone deposit. Int J Min Miner Eng 2021;12(1): 67-83.

[5] Du Plessis M. Marikana general geotechnical information (unpublished). North west, republic of South Africa. 2016.

[6] Balakrishna M. An assessment of the economic viability of mining the UG2 Reef within the no.12 Shaft lease area, Impala Platinum Limited. MSc Thesis. Pretoria, RSA: University of Pretoria; 2006.

[7] Hoek E, Kaiser P, Bawden W. Support of underground excavations in hard rock. Rotterdam: AA Balkema; 1995.

[8] Barton N, Lien R, Lunde J. Engineering classification of rock masses for the design of tunnel support. Rock Mech 1974;6: 189-236.

[9] Watson B. A rock mass rating system for evaluating stope stability on the Bushveld Platinum mines. J S Afr Inst Min Metall 2004:230.

[10] Darling P. SME mining engineering handbook. 3rd ed. Englewood, Colorado USA: Society for Mining, Metallurgy, and Exploration; 2011.

[11] Palmstrom A. Application of the volumetric joint count as a measure of rock mass jointing. Björkliden, Norway. In: Proceedings of the international Symposium on Fundamentals of Rock Joints, Sweden; 1985. p. 97-110.

[12] Bieniawski Z. Engineering rock mass classification. 1st ed. New York, USA: Wiley; 1976.

[13] Swart A, Human J, Harvey F. Rock engineering challenges. J S Afr Inst Min Metall 2005;105:104.

[14] Potvin Y. Empirical open stope design in Canada, Ph.D Thesis. Columbia, Vancouver: University of British; 1988.

[15] Hutchinson D, Diederichs M. Cablebolting in underground mines. Canada: BiTech Publishers Ltd; 1996. 